\title{
A abordagem instrumental no ensino de Língua Inglesa e a proposta de formação humana e profissional em cursos técnicos na modalidade subsequente
}

\author{
Letícia Priscila Pacheco ${ }^{1}$
}

\begin{abstract}
Resumo
Este artigo apresenta uma revisão bibliográfica e discussão sobre a abordagem instrumental no ensino da língua inglesa em cursos técnicos, retratando especificamente o âmbito da rede federal de educação técnica $e$ tecnológica. 0 ensino da língua inglesa como auxiliar na formação profissional e com vistas à formação humana é base para a discussão de metodologias e abordagens adequadas para os discentes de cursos técnicos na modalidade subsequente ao ensino médio. Após uma breve retomada do histórico da rede federal de educação técnica e tecnológica, é debatido o papel do profissional técnico no mundo do trabalho atual e o modo como a aprendizagem de uma língua estrangeira pode auxiliar na formação desse sujeito ao capacitá-lo para uma melhor leitura de mundo e o exercício de seu protagonismo profissional e pessoal. Também é abordada a aprendizagem da leitura em língua estrangeira a partir da perspectiva cognitiva e, especialmente, com foco na aplicação de estratégias de leitura. Conclui-se que o ensino de línguas dentro da proposta do ensino técnico pode ser um aliado para o desenvolvimento linguístico, comunicativo e profissional, capacitando o trabalhador para tarefas de maior relevância e complexidade. Verifica-se ainda, que o desenvolvimento das habilidades comunicativas pode auxiliar na superação das dificuldades de aprendizagem e promover a melhora no desempenho do estudante que busca a qualificação para o trabalho e para a vida.
\end{abstract}

Palavras-chave: Inglês instrumental. Ensino de línguas. Ensino técnico.

\begin{abstract}
This paper presents a bibliographic review and discussion about the instrumental approach for language teaching in technical courses, depicting the scope of the federal network of technical and technological education. The foreign language teaching as an aid in professional training and with a view to human formation is the basis for the discussion of methodologies and appropriate approaches for the students of technical courses in the modality after high school. After a brief recovery of the history of the federal network of technical and technological education, it is debated the role of technical professionals in the current world of work and how learning of a foreign language can help in the formation of the subject and enable him for a better reading of the world and the exercise of his professional and personal protagonism. It is also addressed the learning of foreign language reading from the cognitive perspective, and especially focused on the application of reading strategies. It can be concluded that the language teaching within the proposal of technical education can be an ally for the linguistic, communicative and professional development, empowering the worker for more relevant and complex tasks. It is also verified that the development of communicative skills can help in overcoming learning difficulties and promote improvement in student performance seeking qualification for work and life.
\end{abstract}

Key words: Instrumental English. Language teaching. Technical education.

\footnotetext{
${ }^{1}$ Mestra em Letras e professora do Instituto Federal de Educação, Ciência e Tecnologia Sul-rio-grandense IFSul campus Venâncio Aires.
} 


\section{Introdução}

Falar sobre linguagem é falar sobre os meios de interação do ser humano. A linguagem é sempre essencial para que as relações sejam construídas e é por meio dela que expressamos e construímos ideias, opiniões, o que nos insere no meio social. A aquisição da linguagem passa por uma série de processos que culminam na estruturação da fala, da escrita e da compreensão leitora e auditiva. Comunicar-se é existir, fazer-se presente. Muitas são as barreiras que se erguem frente às pessoas que apresentam dificuldades comunicativas.

Hoje, o mundo globalizado faz com que a língua materna não seja mais suficiente para uma comunicação integral. Mesmo tendo competência para se comunicar com adequação em sua primeira língua, sempre haverá situações em que uma ou mais línguas estrangeiras precisam ser utilizadas. Ao falarmos em globalização e das fronteiras culturais, na necessidade de conhecer as inovações tecnológicas e científicas que possibilitam maior correção formativa e possibilidades de trabalho e desenvolvimento intelectual, vemos 0 quanto se faz importante o estudo e, consequentemente, o ensino de línguas estrangeiras para os profissionais e estudantes das mais diversas áreas de atuação.

No contexto da educação profissional, o ensino de línguas estrangeiras se faz também necessário. Quanto a este nicho, podemos citar o grande salto que foi dado em relação à educação profissional e tecnológica no Brasil nos últimos anos. Diante da oferta de formação e de qualificação técnica profissional, disponibilizadas pelas instituições federais de educação técnica e tecnológica, cremos que, além de capacitar os estudantes das instituições federais estudantes para cargos técnicos, podemos oferecer-lhes maior possibilidade de crescimento pessoal e intelectual.

No mundo do trabalho, em que é preciso que o profissional seja comunicativo, crítico e tenha conhecimento de mundo, é inaceitável que os recursos humanos sejam apenas capacitados de acordo com suas áreas técnicas. É fundamental que possamos auxiliá-los em sua formação no âmbito cultural, no seu crescimento pessoal e ainda na ampliação de seus horizontes, preparando-os, assim, para uma realidade em que é exigido muito mais do que aptidão para manusear maquinários de produção em série. Há necessidade de vivenciar processos de discussão, tomada de decisões e exercício da liderança e, assim, motivá-los para inúmeras possibilidades de inovação das tecnologias. 
O estudo de língua inglesa, o qual é destacado neste artigo, é abordado a partir do conceito de ensino de línguas estrangeiras para propósitos específicos (ESP), abordagem que visa à ampliação de conhecimentos relativos à cultura da língua, bem como de conhecimentos básicos sobre a estrutura do idioma, seu vocabulário, fonética, sintaxe, entre outros, com foco nas necessidades específicas do público atendido (BASTKURMEN, 2010, RAMOS, 2004, VILAÇA, 2010, JOHNS \& PRICE-MACHADO, 2001). A proposta de ESP, quando voltada aos cursos técnicos de eixo de controle e processos industriais, por exemplo, prioriza a aproximação dos estudantes do vocabulário técnico referente ao eixo, capacitandoos a operar maquinário que apresenta instruções no idioma e estabelecer comunicação interpessoal em situações que exijam conhecimento básico.

A oferta da disciplina de inglês instrumental para o curso subsequente ao ensino médio reconhece a necessidade de formação dos profissionais da área em tópicos específicos da língua, visando principalmente à capacitação destes para a leitura e interpretação de textos presentes nos mais diversos gêneros que permeiam a profissão. No que diz respeito à operacionalização de maquinário específico, a habilidade de leitura é essencial para que o trabalhador possa exercer suas atividades com adequação e segurança, de forma que, ao surgir alguma dificuldade, esta possa ser esclarecida pelo uso do manual de instruções e de demais informações que possam ser úteis no momento. A rapidez da evolução tecnológica aliada ao pressuposto de que profissionais capacitados devem ter conhecimento da língua predominante nos países em que as tecnologias de ponta são desenvolvidas, faz com que muitos manuais e indicadores não sejam traduzidos, sendo a língua inglesa concebida como “língua internacional”, pertencente ao mundo todo. (MATSUDA, 2012, LEFFA, 2006).

É visto que, diante da realidade, a disciplina de língua inglesa é oferecida aos estudantes dentro dos cursos com um curto tempo de duração. Por isso é dada ênfase na compreensão em leitura de textos de gêneros específicos: manuais de instrução, avisos de segurança, entre outros. Para que o tempo disponibilizado possa ser otimizado, é necessário que seja adotada uma metodologia adequada e que o material utilizado possa suprir as necessidades de conhecimento da língua estrangeira, oferecendo aos estudantes um curso para fins específicos.

A otimização do tempo deve acompanhar ainda a motivação dos estudantes. Mais do que instrumentalizá-los em uma língua estrangeira, é importante que o contato com a língua 
possa fazer sentido para suas vidas. Pessoas que não têm grandes ambições de viagens ou estudos aprofundados que exijam a comunicação em língua inglesa frequentemente não demonstram interesse em aprender a língua. Porém, uma das missões do professor de línguas estrangeiras em cursos técnicos, senão a mais nobre, é buscar despertar o interesse em saber mais, demonstrar o quanto é necessária a comunicação em uma ou mais línguas estrangeiras para almejar melhores possibilidades profissionais e oportunizar crescimento pessoal.

Este artigo busca sugerir a uma metodologia de ensino de língua estrangeira adequada a um público com restrições de tempo, com histórico de um intervalo prolongado na sua formação escolar e ainda, com objetivos profissionais específicos, tratando assim do ensino da língua inglesa para fins específicos. Sabemos que não se trata de oferecer um curso nas condições ideais de aprendizado da língua estrangeira com foco na conversação e formação linguística integral, mas dar uma resposta pragmática à sociedade, que questiona o professor e pesquisador de línguas estrangeiras sobre a importância e a necessidade de manter a disciplina de inglês instrumental em cursos técnicos profissionalizantes. Buscamos respostas sobre como otimizar o tempo dedicado à disciplina para construir a aprendizagem a longo prazo, estimulando os estudantes a continuarem buscando os conhecimentos sobre a língua estrangeira, solidificando ainda mais suas habilidades comunicativas dentro e fora de sua profissão.

\section{Trajetórias da Rede Federal de Educação Técnica e Tecnológica}

A Rede Federal de Educação Técnica e Tecnológica que conhecemos atualmente teve origem a partir das escolas de aprendizes artífices, criadas em 1909, pelo presidente da república Nilo Peçanha. A proposta de expansão iniciada em 2005 visa ao atendimento das diversas regiões com educação de qualidade e qualificação pessoal e profissional, bem como à descentralização da oferta de cursos técnicos, tecnológicos e superiores das capitais e do litoral do país.

Há uma preocupação com a formação integral do ser humano, qualificação profissional, pesquisa e desenvolvimento de novos processos. Mesmo tendo como carro chefe a formação de profissionais da área técnica e, consequentemente, dando mais ênfase para tais disciplinas, há interesse na formação do homem como um todo. Segundo a Secretaria de 
Educação Profissional e Tecnológica (SETEC) do Governo Federal (BRASIL, 2010, p. 03), o foco dos Institutos Federais é a justiça social, a equidade, a competitividade econômica e a geração de novas tecnologias. Há, ainda, a preocupação com a formação humana e cidadã, a qual deve preceder à qualificação para o exercício da laboralidade e pautar-se no compromisso de assegurar aos profissionais formados a capacidade de manter-se permanentemente em desenvolvimento.

Da mesma forma, a educação profissional e tecnológica afirma-se como uma política pública, à medida que proporciona ambiente escolar apropriado e gratuito para a população. Há um pensamento norteador de que não apenas a educação é necessária para proporcionar melhores condições para a população carente. 0 estudante não poderá alcançar seu melhor desempenho se ainda enfrentar dificuldades com moradia, transporte, alimentação e saúde. Dentro de uma perspectiva de inclusão, o governo federal vem realizando várias ações nesse sentido por meio dos institutos federais.

A SETEC (BRASIL, 2010, p. 06) explica que

A concepção de Educação Profissional e Tecnológica (EPT) orienta os processos de formação com base nas premissas da integração e da articulação entre ciência, tecnologia, cultura e conhecimentos específicos e do desenvolvimento da capacidade de investigação científica como dimensões essenciais à manutenção da autonomia e dos saberes necessários ao permanente exercício da laboralidade.

A ideia de fornecer ensino profissionalizante nasceu da necessidade de mão de obra nas indústrias. No início de sua implantação, por volta de 1909, foi utilizada largamente pela classe dirigente como meio de contenção do que era considerado "desordem social". Chamavam-se Escolas de Aprendizes Artífices e associavam-se à qualificação da mão de obra e ao controle social dos filhos da classe proletária, jovens em situação de risco social, potencialmente sensíveis à aquisição de vícios "nocivos à sociedade” e à construção da nação (MEIRELES, 2007, p. 33-50).

A partir de 1942, as Escolas de Aprendizes Artífices foram transformadas em Escolas industriais e técnicas, fornecendo nível de instrução equivalente ao secundário. Bem mais tarde, em 1994, foram renomeadas como Centros Federais de Educação Tecnológica (CEFETs), e em 1998 foram implantados novos centros. Já a partir de 2003 novas medidas foram discutidas e implantadas de forma a orientar o ensino técnico para a formação integral 
de cidadãos trabalhadores. Junto com esta visão integral reafirma-se a intenção de unir o ensino tecnológico às necessidades locais e regionais, tornando-o mais eficaz em menos tempo e, ainda, suprindo as necessidades de formação profissional nas mais diversas regiões do país.

Ao considerar a importância da integralidade dentro do ensino técnico há que se firmar o compromisso com formação, transformação e enriquecimento de conhecimentos, objetivos capazes de ampliar as possibilidades e atribuir maior sentido às experiências de vida, isto é o que valoriza este trabalho.

Desenvolver um trabalho mais próximo da realidade do estudante é essencial para que a aprendizagem seja real, para que o tempo dispensado para as atividades discentes tenham efeito na rotina do estudante que também é trabalhador e busca o curso técnico como possibilidade de ampliação das oportunidades no âmbito profissional e pessoal. De modo geral, na prática da docência na educação técnica e tecnológica, verifica-se que os estudantes que se matriculam em cursos técnicos na modalidade subsequente apresentam muitas dificuldades de aprendizagem, muitas vezes por terem ficado afastados da escola por muitos anos. Da mesma forma, esta característica se reflete na aprendizagem de uma língua estrangeira, fato que denota a pouca exposição ao idioma estrangeiro ao longo da vida e, talvez, poucas oportunidades de aprendizagem da língua para a comunicação e não para apenas para a compreensão de sua estrutura.

Hoje, a proposta das instituições de ensino técnico é que a educação técnica seja vista mais como um complemento para a formação humana do que uma mera preparação para o trabalho ou ferramenta supletiva de aprendizagem (OLIVEIRA, 2011, BEZERRA, 2012). De acordo com o Parecer n 17/1997 da Câmara de Educação Básica, a valorização do ensino médio não significa a desvalorização do ensino técnico e vice-versa.

Os cursos subsequentes podem apresentar uma carga de disciplinas básica. Componentes curriculares como português instrumental, inglês instrumental e informática fazem parte da grade de alguns cursos. Com a perspectiva da formação integral, as disciplinas da área de comunicação proporcionam crescimento para todos os estudantes, mas principalmente para aqueles que apresentam dificuldades na leitura, escrita e até mesmo de construção de sua fala e argumentação. Através de discussões e das propostas de leitura, os 
futuros profissionais técnicos são instigados a desenvolver competências discursivas, argumentativas e tantas outras tão relevantes para sua capacitação no ambiente de trabalho.

Com a oferta de línguas estrangeiras é possível despertar o interesse na qualificação pessoal em uma ou mais línguas. Atualmente grande parte do maquinário utilizado pelas empresas das mais diversas áreas é importada, o que pode dificultar a sua operacionalização por profissionais que não estejam qualificados para leitura técnica ou mesmo para a comunicação em língua estrangeira. Os manuais dos equipamentos utilizados tanto para estudo quanto para o trabalho efetivo são apresentados em língua inglesa, o que leva as empresas a exigirem que seus trabalhadores tenham tal qualificação para proporcionar mais opções no manuseio de tais equipamentos.

Considera-se importante a proficiência em língua estrangeira não apenas para 0 ambiente de trabalho, mas ainda como uma ferramenta de acesso à cultura. A instrumentalização para a comunicação em uma língua estrangeira possibilita que o indivíduo tenha acesso a fontes de pesquisa mais atualizadas, informações de diversas ordens e também tenha conhecimento sobre a cultura dos demais países, à medida que terá melhores condições de ler e compreender os textos disponíveis nos meios de comunicação (OLIVEIRA, 2011, FERRAZ, 2012, ARNT, 2018). O acesso ao aprendizado de línguas estrangeiras pode acrescentar muito na carreira profissional do técnico, já que estaria capacitado para a pesquisa e produção de novas tecnologias, ou mesmo a otimização de processos e recursos existentes. A busca da inovação parte do estudo e levantamento de pesquisas que estão sendo realizadas em outros países e, à medida que aprimora sua comunicação em língua estrangeira, o profissional amplia sua capacidade de comunicação de modo geral.

\section{0 processo de aprendizagem de uma nova língua}

A língua inglesa é uma das línguas mais aprendidas como língua estrangeira em todo o mundo. Como língua estrangeira nos referimos aqui a qualquer língua que seja utilizada além da língua de materna do falante. As pessoas buscam aprimorar seus conhecimentos sobre o idioma pelos mais diversos motivos. Conforme a necessidade individual do aprendiz, diferentes formas de estudo podem ser ofertadas. Na sala de aula convergem as mais diversas motivações, considerando contextos específicos de diferentes classes escolares. É sempre 
um desafio para o professor alcançar as motivações presentes na sua sala de aula de forma mais abrangente, porém, quanto maior for a adesão da turma à proposta do professor, maior será a probabilidade de sucesso na aprendizagem da língua estrangeira.

Pensar o ensino-aprendizagem de segunda língua por meio de uma abordagem cognitiva e interacionista é acreditar que a aprendizagem é um processo. Brown (1994, p. 60) esclarece que a cognição se desenvolve como um processo de movimento de um estado de dúvidas e incertezas (desequilíbrio) para estágios de resolução e certeza (equilíbrio) e então novamente uma dúvida futura, que será então solucionada. A concepção de observar a aprendizagem como um processo cíclico e fluente conversa com os estudos de interacionistas, visto que estamos sempre aprendendo a partir das situações a que somos expostos, construindo relações de sentido e ampliando conhecimentos em amplitude e complexidade. A partir deste pensamento, se crê que o aprendizado de uma língua estrangeira envolve uma série de representações e assimilações internas, que ao longo do tempo irão refletir no uso da língua. Lima (2007, p. 23) acredita que

É necessário superar, também, a concepção de que o conhecimento seja apenas informação. 0 conhecimento resulta da "organização" de informações em redes de significados. Esta organização não é uma organização qualquer, pois deve ser passivel de ser ampliada por novos atos de conhecimento, por outras informações ou ainda ser reorganizada em função de atividades específicas à apropriação do conhecimento.

As mais diversas habilidades envolvidas no processo de aprendizagem devem ser praticadas constantemente. A consolidação das memórias ligadas à linguagem e, consequentemente, ao desenvolvimento das habilidades comunicativas, está relacionada à frequência e à intensidade com que essas informações são acessadas (BADDELEY, 2011, IZQUUIERDO, 2018). Abordagens conexionistas acreditam que a ativação das informações se reflete no estímulo dos nódulos neurais, possibilitando o reforço das sinapses cerebrais e, desta forma, a consolidação das memórias e a automatização do caminho a ser percorrido pelo pensamento para que essas memórias sejam acessadas. Sobre este processo, Kandel et al (2014, p. 1256) explicitam que o aprendizado se refere a uma mudança no comportamento que resulta da aquisição de conhecimento acerca do mundo, e a memória é o processo pelo qual esse conhecimento é codificado, armazenado e posteriormente evocado. Da mesma forma, a aprendizagem de uma nova língua passa por todos esses processos e, mais 
precisamente de forma diferenciada nos diferentes aspectos da linguagem: sintáticos, semânticos, pragmáticos.

Como uma teia, as habilidades comunicativas estão intimamente interligadas, uma vez que, para estabelecer um evento comunicativo, o indivíduo precisa entender o que fala seu interlocutor e deve ser entendido por ele. No caso da escrita, é preciso entender o que se lê e também ter habilidades de escrita que possibilitem o entendimento por parte dos outros leitores.

Ao pensarmos o ensino de língua estrangeira dentro da perspectiva cognitiva, nos vem a ideia de um ensino voltado para a potenciação das possibilidades de memorização $e$ consequente construção de um sistema linguístico organizado. Dentro das possibilidades atuais, em que o tempo é reduzido, o aprimoramento e a aceleração da aprendizagem podem fazer diferença no processo de ensino-aprendizagem, à medida que o professor passe a entender os processos cognitivos inerentes à aprendizagem e a potência da carga afetiva envolvida nos processos de motivação para a aprendizagem. Almeida Filho (1993, p. 08) acredita que "numa fase inicial de aprendizagem de uma nova língua predomina a busca de redução de incertezas especialmente quando os interlocutores são relativamente desconhecidos um do outro". Assim, quanto maior o diálogo e a troca de informações no processo de ensino e aprendizagem, melhor será o resultado da parceria estabelecida entre professor e estudantes.

\subsection{A leitura em língua estrangeira}

A leitura é uma das habilidades humanas que mais acrescenta à sua formação. Através dela são abertas novas possibilidades para os leitores, que expandem sua imaginação, conhecimentos sobre a língua e ainda o conhecimento de mundo. Morais (1996, p. 112) entende que

O objetivo dos processos específicos da leitura é representar material escrito sob uma forma utilizável pelo resto do sistema cognitivo. A capacidade de leitura pode, por conseguinte, ser definida como o conjunto dos processos perceptivos que permitem fazer com que a forma física do sinal gráfico deixe de constituir um obstáculo à compreensão da mensagem escrita. 
A construção do sentido pela leitura passa por diversas etapas e faz com que o leitor aumente seus conhecimentos, melhore suas habilidades cognitivas e, consequentemente, qualifique seu trabalho ao ter melhores condições de interpretar as situações à sua volta.

Marcuschi (2008, p. 230), a respeito da compreensão na leitura, salienta que compreender não é apenas uma ação linguística ou cognitiva. Para ele, é muito mais uma forma de inserção no mundo e um modo de agir sobre o mundo na relação com o outro dentro de uma cultura e uma sociedade. A partir do que lê, o homem constrói sua realidade e perspectivas. A leitura muito mais do que o crescimento linguístico, pode ampliar horizontes e até criar novos caminhos. A compreensão, conforme afirmado por Marcuschi (2008), é muito mais do que a cognição ou a linguística separadamente, é um conjunto de esforços para que a plenitude da leitura possa ser alcançada na interação social.

A leitura tem caráter individual e coletivo. Ao mesmo tempo que ela tem o poder de estimular a reflexão do indivíduo leitor, ela possibilita a troca de informações e a integração de ideias. 0 mesmo texto, lido em diferentes momentos da vida do leitor, pode ter significados diferentes para ele, despertando ou ocultando sentidos de acordo com a experiência pessoal deste leitor. Smith (1989, p. 61) acredita que a leitura proporciona ao leitor novas estruturas para a percepção do mundo e para a organização da experiência. As habilidades de leitura no mundo do trabalho exercem um papel fundamental para a formação do trabalhador, para a capacitação e consequente crescimento em seu campo de atuação. À medida que o trabalhador estiver mais bem preparado para realizar suas leituras, interpretar e compreender as informações que chegam até ele nos mais diversos formatos, a sua capacidade de elaboração de tarefas, compreensão de diretrizes e de especificações técnicas também apresentarão melhor desempenho.

Durante a leitura, fatores textuais e extratextuais são analisados, muitas vezes inconscientemente pelo leitor no contato com um texto. Assim, índices como: forma, fonte, cores, padrões, conhecimento e experiências prévias, podem ser extremamente importantes no momento da leitura, porque guiam o leitor por pistas tipográficas norteadoras para uma melhor compreensão, possibilitando que o leitor fala inferências quanto à origem, proposta $e$ objeto principal do material a ser compreendido na leitura. Smith (1989, p. 85) afirma que existem outros tipos de informação não-visual, além do conhecimento da linguagem. Para ele, o conhecimento sobre o assunto é igualmente importante. 0 conhecimento prévio exerce 
função de organização das hipóteses que o leitor cria durante sua leitura, confirmando-as ou não ao longo do processo de compreensão das palavras e estruturas linguísticas presentes ao longo do texto.

A aquisição de vocabulário é uma das peças fundamentais para a aquisição de uma língua, seja essa materna ou não. Desde pequenos caminhamos pelo mundo das palavras, ouvindo-as, praticando-as, testando possibilidades. A aquisição do léxico é um processo que mesmo depois de muitos anos permanece ativo, apesar da diminuição no ritmo de palavras novas que são aprendidas. Sempre que lemos, vemos ou ouvimos algo novo, o número de possibilidades que temos para expressarmos nossas ideias aumenta e a linguagem é aprimorada. Em relação à competência leitora, acredita-se que há uma relação íntima entre a frequência dos eventos de leitura e a capacidade que o leitor tem de realizar esta tarefa. Dentro desta perspectiva, há um acordo de que quanto mais o estudante ler, mais palavras ele terá condições de entender. Ainda dentro do entendimento da leitura como forma de estímulo cognitivo, Smith (1989, p. 211) explica que as consequências gerais das experiências de leitura são um aumento da memória e do conhecimento específico. Segundo ele, a única maneira possivel de se aprender todas as convenções da ortografia, pontuação, letras maiúsculas e minúsculas, parágrafos e até mesmo gramática e estilo é através da leitura.

Há uma série de regras e padrões linguísticos que mudam de acordo com a língua estudada. Estes padrões são aos poucos apresentados aos estudantes e estes, dentro de suas possibilidades de assimilação, vão integrando-os às suas produções comunicativas. A aquisição de aspectos linguísticos mais complexos como a estrutura frasal, ordenação textual, papel de determinados conectivos é, muitas vezes, a parte em que os estudantes de língua estrangeira mais demonstram dificuldades. Há casos em que a dificuldade apresentada pelo estudante está ligada aos padrões estruturais de sua língua materna, quando a primeira língua apresenta um distanciamento maior da segunda.

Quando tratamos da leitura em língua estrangeira, o processo é parecido, porém devemos considerar que, em grande parte dos casos de estudantes de língua estrangeira, não há um grande período de tempo de exposição à língua estrangeira. Mesmo que os meios de comunicação e as novas tecnologias tragam sempre mais palavras estrangeiras que são agregadas ao nosso cotidiano, grande parte do vocabulário e estruturas da língua estrangeira 
ainda precisam ser apresentados pelo professor, em atividades que envolvam a leitura e conversação na sala de aula.

Podemos ainda ressaltar a diferença entre os processos de compreensão em língua materna e em língua estrangeira. Quando ocorre o processamento da leitura em língua materna, o leitor consegue adquirir novo vocabulário com base no conhecimento oral, ou seja, tudo o que ele aprendeu antes de ter as habilidades da leitura e escrita também serve de parâmetro para as relações feitas durante o processo de assimilação do texto lido. Já as relações feitas em língua estrangeira requerem um foco maior nas construções linguísticas. A estrutura frasal, relações de sentido dentro do texto são vistas mais facilmente através das regras aprendidas pelos estudantes, por meio da forma como a língua materna é vista: mais automática e relacionada ao sentido. Lado (1964, p. 14) explica que as diferenças mais importantes entre duas línguas não são referentes às palavras, vocabulário, mas sim às estruturas de cada uma das línguas, em seu sistema e padrão de regras, entonação, consoantes e vogais.

O uso de materiais condizentes com os objetivos dos leitores poderia promover a motivação e tornar os objetivos mais delineados. Ao visualizar oportunidades de comunicação semelhantes à realidade, 0 aprendiz de segunda língua acredita estar progredindo no processo de aprendizagem, sente-se seguro para experimentar novas possibilidades.

Pesquisas apontam para possíveis relações entre o nível de proficiência em língua materna e o desempenho no aprendizado da leitura em uma segunda língua (BENCKE, 2008; BRAUER, 2009). De um lado, há a hipótese de que quanto maior o léxico adquirido pelo sujeito, mais facilmente esse irá aprender uma segunda língua, pois, assim, teria mais possibilidades de estabelecer relações entre seus conhecimentos de primeira e de segunda língua. Já outra hipótese sugere que quando o sujeito tiver um léxico mais amplo, tais construções poderiam servir como empecilho para as novas construções adquiridas com a segunda língua, devido ao fato de que a estrutura de certas línguas é muito diferente de outras, muitos padrões variam entre as línguas. Porém não podemos nos ater apenas ao léxico e aos efeitos de conhecer mais ou menos palavras de uma língua. 0 conhecimento sobre a estrutura sintática e demais características da língua também têm grande influência na medição do nível de proficiência em alguma língua, seja ela materna ou estrangeira. 
Em termos de língua estrangeira, outro pensamento é de que a fase adulta poderia proporcionar outras possibilidades para a aquisição de uma segunda língua. De acordo com Venturi (2006, p. 124), o indivíduo adulto, em virtude de sua maturação cognitiva, pode se apoiar em estratégias metalinguísticas de processamento (como o uso explícito da gramática, por exemplo), enquanto a criança chega às generalizações por inferência.

O objetivo principal das aulas de língua estrangeira é que os estudantes sejam capazes de comunicar-se na língua-alvo. A leitura é ponto crucial para a comunicação, se estende além da palavra falada, abre possibilidades tão importantes quanto a oralidade. Ao promover o aprendizado, o professor de língua estrangeira precisa de ferramentas variadas que deem conta das habilidades de leitura, escrita, fala e audição. Ao abordar a leitura, um dos papeis do professor é selecionar materiais adequados ao curso e ainda entender os processos envolvidos na leitura e a forma como os sentidos do texto podem ser elaborados pelos estudantes.

Pensando ainda na oferta de disciplinas voltadas para a instrumentalização de uma segunda língua, há uma constante busca por instrumentos de ensino que possibilitem um aprendizado eficaz e concreto; isso, dentro das possibilidades de carga horária disponíveis. Uma alternativa possível seria o ensino e aplicação de estratégias de leitura em textos nas aulas instrumentais de inglês como língua estrangeira.

É necessário abordarmos aqui a relevância das estratégias de leitura para a aprendizagem da língua estrangeira pela abordagem instrumental. Elas estão presentes na rotina dos estudantes, podem auxiliar na organização do pensamento promovendo a melhora dos resultados obtidos. Autores como Oxford (1989), O'Malley et al. (1990) e Silva (2002) abordam as estratégias como ferramentas de aprendizagem de línguas estrangeiras; outros, como Santos (2012) e Souza (2008), pretendem aplicar o uso dessas estratégias como facilitadoras da leitura.

É necessário ressaltar que a escrita e a leitura são habilidades igualmente importantes no processo de aprendizagem de uma língua, e ambos, junto com a fala e a competência auditiva, tornam o processo homogêneo e o aprendiz capaz de comunicar-se com eficiência e adequação nos mais diversos contextos e situações. Quanto a isso, Savignon (1983, p. 08) afirma que: "a competência comunicativa se aplica tanto à língua falada quanto à escrita, assim como a tantos outros sistemas simbólicos". Durante a leitura de um texto em língua 
estrangeira, por exemplo, há uma série de inferências quanto ao significado do que está sendo lido, a começar pelo vocabulário que nem sempre é conhecido em sua totalidade pelo leitor. 0 processo de leitura de um texto exige que o leitor inicie um jogo de probabilidades e possibilidades, buscando em seu léxico significados de palavras que possam ser relevantes para sua leitura.

Ao pensarmos em estratégias de leitura como forma de capacitação inicial de alunos em cursos de inglês instrumental, um grande leque de diferentes estratégias e práticas de ensino de línguas estrangeiras poderia ser citado. Entre as estratégias mais comumente utilizadas, destacamos o apoio em palavras transparentes, skimming, scanning, uso de pistas tipográficas e o uso de dicionário bilíngue. Mesmo com o acesso aos textos, para um aprendiz de língua estrangeira é muito difícil haver a decodificação e posterior interpretação adequada do material quando o leitor não possui conhecimentos linguísticos suficientes para tal atividade. $O$ acesso a materiais autênticos poderia facilitar ou mesmo dificultar a aprendizagem de estudantes em nível iniciante. Silva (2002, p. 27) lembra que “a ‘Hipótese do Princípio Linguístico' sustenta, em linhas gerais, que, para se ler em segunda língua, é preciso ter certo nível de competência linguística nessa língua". Assim, podem ocorrer dificuldades referentes ao léxico, estrutura frasal, e mesmo tópicos gramaticais. Então a pergunta é: como fazer com que os alunos leiam tais textos com pouco tempo de exposição à língua?

A leitura de um texto em uma língua que não se domina pode causar dificuldades. Se muitos leitores ainda têm dificuldades de compreensão de textos em sua língua materna, 0 que dizer de uma língua estrangeira e do tempo cada vez mais curto que é disponibilizado para seu aprendizado. Uma possibilidade para melhorar a compreensão na leitura de textos em língua estrangeira pode ser o uso de estratégias de leitura, que deixariam o aprendiz mais confiante nas representações linguísticas que está produzindo na nova língua, encorajandoo a utilizá-la com mais frequência e naturalidade.

Ao organizar sua leitura a partir de estratégias, o leitor passa a observar itens que indiretamente guiam seu pensamento e suas hipóteses de significação para o texto lido. Como exemplo, podem ser observados índices tipográficos, como a cor da letra, a paginação, a organização do texto por itens ou não, a ocorrência de palavras semelhantes à língua materna, consideradas transparentes, recorrência de termos específicos, orientando a 
interpretação para determinado campos semântico, entre outros. Alguns autores explicam que há diferenças entre os chamados leitores hábeis e os "maus leitores" e a aplicação de estratégias de compreensão escrita poderia dar subsídios para a compreensão do que é lido. O leitor hábil não enfrentaria tantas dificuldades para compreender o que é lido, porque a partir de sua experiência prévia construiria caminhos interpretativos para organizar 0 pensamento, já o "mau leitor" precisaria de maior auxílio de estratégias e aporte de conhecimentos para conseguir uma leitura mais clara. Logo, com a aplicação de estratégias de leitura pode haver uma diferenciação no aprendizado dos dois grupos. Morais (1996, p. 167) afirma que trabalhos mostraram que a utilização mais importante do contexto pelos maus leitores é uma consequência de sua inferioridade no nível da decodificação. Assim sendo, a decodificação insuficiente ou mais lenta que o conhecimento derivado do contexto intervém para permitir o reconhecimento da palavra.

Por outro lado, Morais (1996, p. 168) também escreve que certas características estatísticas dos contextos habituais em leitura fazem que não seja necessário atingir níveis de capacidade muito elevados para que o papel do contexto se torne desprezível e, ainda, só o reconhecimento de um número considerável de palavras na frase pode criar um contexto suficientemente restritivo para permitir adivinhar corretamente a palavra-alvo. Portanto, se o leitor tiver um bom conhecimento do vocabulário da língua e tiver acesso a um texto de contexto relativamente fácil de ser compreendido, a sua habilidade de leitura poderá ser muito mais eficaz. Se este mesmo leitor tiver acesso a um texto com maior dificuldade de identificação do contexto, poderá não ter tanto sucesso em sua leitura, porém ainda terá grandes chances de entender o texto ao utilizar estratégias de leitura.

Santos (2012, p. 50) apresenta o apoio nas palavras transparentes, ou seja, os cognatos, como uma das estratégias para facilitar a compreensão na leitura em língua estrangeira. Segundo a autora, mesmo que os estudantes não possam compreender alguns detalhes do texto, eles podem ter uma ideia geral sobre seu conteúdo a partir da identificação das palavras transparentes. Segundo Souza (2008, p. 234), os cognatos têm sido vistos, quase sempre, como elementos facilitadores do processo de leitura em língua estrangeira.

Às vezes não é apenas o léxico que torna a leitura mais difícil, certas construções gramaticais podem apresentar diferenças significativas em relação à língua materna, podem confundir e impossibilitar a compreensão de alguma ideia do texto lido. Quanto a isso, Oxford 
(1989, p. 44-45) afirma que às vezes os estudantes cometem erros por generalizar as regras que aprenderam ou transferir expressões de uma língua para outra, tipicamente de sua língua materna para a nova língua.

Para facilitar a leitura inicial de um texto específico no qual se encontram palavras de difícil entendimento para o leitor, uma sugestão é que, ao passar os olhos pelo mesmo em uma leitura inicial, possam ser identificadas palavras-chave, imagens e demais índices que possam facilitar a compreensão do seu tema geral. Esta estratégia é conhecida como skimming. Santos (2012, p. 59) explica que skimming está associado a uma leitura rápida para a ideia geral, e não é sempre que esse objetivo coincide com o propósito da leitura. Sendo assim, é ainda importante a instrução de como utilizar determinadas estratégias em diferentes situações de leitura. Ainda seguindo a proposta de dinamização da leitura, Smith (1989, p. 201) salienta que qualquer esforço por parte de um leitor, para identificar palavras uma de cada vez, sem aproveitar a vantagem de sentido como um todo, indica um fracasso para a compreensão.

Ao realizar posteriormente uma leitura mais aprofundada, já com uma noção inicial de significado, o leitor terá então mais facilidade em entender ideias mais específicas apresentadas pelo autor, desta vez relacionando significados dentro e fora do texto, utilizando seu conhecimento prévio, mesmo que pequeno, sem ser necessário focar sua leitura em cada palavra, mas no texto como um todo. Oxford (1989, p. 43) exemplifica da seguinte forma:

Estratégias para receber e enviar mensagens são ferramentas necessárias. Uma estratégia conhecida como captar a ideia rapidamente, ajuda os aprendizes a localizar a ideia principal através de Skimming ou os pontos mais relevantes através de Scanning. Esta estratégia demonstra que não é necessário que os aprendizes focalizem em cada palavra separadamente.

O uso de dicionário bilíngue também pode ser visto como estratégia. Para que a consulta ao dicionário seja eficaz, o estudante precisa saber fazer a busca pelo verbete e ainda saber reconhecer as diversas classes de palavras. Santos $(2012$, p. 69) lembra que ao tentar identificar o sentido procurado num dicionário, não precisamos ler todo o verbete em detalhes. Geralmente um scanning é suficiente para nos ajudar a encontrar a informação que 
procuramos. 0 estudante irá pesquisar apenas as palavras essenciais à compreensão, e não todas as palavras do texto.

Muitas vezes ao fazer a pesquisa no dicionário, os estudantes ainda terão que criar hipóteses e fazer inferências sobre o sentido da palavra no contexto em que está inserida.

As inferências fazem parte do processo de compreensão em leitura, isto acontece porque o material lido não apresenta todos os detalhes para o leitor, este precisa buscar pistas e indícios que conduzam a leitura em seu conhecimento de mundo e mesmo em pistas dentro do texto.

Em modos gerais, para conseguir uma compreensão satisfatória da sua leitura, o leitor precisa identificar o tipo de texto que está lendo e o propósito deste texto. Santos $(2012, \mathrm{p}$. 81) relata que saber identificar o propósito comunicativo de um texto ajuda o leitor a entender por que (e para quem) o texto foi escrito e essa identificação, por sua vez, auxilia o leitor a localizar outros recursos usados pelo autor para atingir seus objetivos. Porém, para que possa identificar o texto, é preciso utilizar seu conhecimento de mundo, suas experiências prévias de leitura. A experiência adquirida ao longo de seu histórico de leitura precisa ter sido categorizada, ou seja, os textos lidos precisam ser subdivididos em tipos e objetivos distintos, para que possam ser aplicados posteriormente a outras experiências de leitura e que esta memória seja acessada com sucesso.

Discutiremos a seguir sobre o desafio da disciplina de inglês instrumental a partir da abordagem do ensino de língua estrangeiras para propósitos específicos, buscando subsídios para

\section{A disciplina de inglês instrumental como desafio}

Nos casos em que os aprendizes têm contato com situações reais de comunicação, não simuladas, do uso da língua estrangeira, mesmo havendo um estranhamento inicial, há probabilidade de que as habilidades de compreensão auditiva e a fala sejam desenvolvidas com mais rapidez; especialmente se considerarmos as variantes regionais e informais da língua, o que envolve dentre outros aspectos o emprego de expressões idiomáticas e verbos frasais. Em contrapartida, habilidades como a leitura e a escrita de textos, principalmente os 
formais, são desenvolvidas de forma mais eficaz em situações de aprendizagem que envolvam explicitação dos conteúdos, como situações de sala de aula com a presença de um professor.

Quando os estudantes apresentam objetivos específicos para o aprendizado do idioma, tendem a demonstrar mais motivação e entusiasmo no desempenho das tarefas. Broughton et al (1980, p. 07) destacam que “em situações de aprendizado de língua estrangeira deste tipo, centenas de milhares de aprendizes de inglês tendem a ter uma motivação instrumental para a aprendizagem da língua estrangeira". Esta motivação instrumental diz respeito às possibilidades de aplicação prática dos conhecimentos adquiridos sobre a língua, bem como as situações comunicativas que farão o estudante refletir sobre a sua atual condição de comunicação na língua estrangeira.

Para Lima (2007, p. 25), o ser humano aprende somente as formas de ação que existirem em seu meio, assim como ele aprende somente a língua ou as línguas que aí forem faladas. A partir desta ideia, a neurocientista afirma ainda que a cultura é constitutiva dos processos de desenvolvimento e de aprendizagem. Portanto, expor os aprendizes a situações que envolvam diversas habilidades, contextualizar a linguagem dentro de situações de uso comum e ainda possibilitar o desenvolvimento da função simbólica, auxilia no aprendizado de uma língua estrangeira e também na organização da linguagem e no aprendizado de conhecimentos das mais diversas áreas.

Há uma preocupação em adaptar os cursos a uma metodologia para o ensino de língua estrangeira de acordo com as reais necessidades e possibilidades dos alunos envolvidos no processo. Cada perfil de estudante demanda um esforço do professor em conhecê-lo e, consequentemente, fazer uma opção adequada para o curso oferecido.

O ensino de línguas estrangeiras busca ampliar conhecimentos de mundo dos estudantes e não apenas ajudá-los a estabelecer comunicação eficaz em outra língua além da sua. Lima (2007, p. 26) explica que o desenvolvimento do cérebro é função da cultura e dos objetos culturais existentes em um determinado período histórico e que, sendo assim, novos instrumentos culturais levam aos novos caminhos de desenvolvimento. 0 aprendizado sobre os elementos da cultura geral possibilita a abertura da consciência do estudante para aspectos da sociedade que antes passariam despercebidos.

Ampliar os horizontes perceptivos do sujeito traz benefícios para sua atuação como ser social, como sujeito de sua vida e responsável por seu crescimento intelectual. Portanto, 
para que seja possivel alcançar êxito com os estudos em língua estrangeira, tanto o professor quanto os alunos devem estar envolvidos no processo, buscando os mesmos objetivos, conscientes de todas as etapas do processo de aprendizagem, das dificuldades e de todo esforço empregado nesta tarefa. Mesmo assim, podemos dizer que ainda que existam dificuldades, o momento de aprendizagem precisa ser positivo para a motivação e interação. É necessário que haja aprendizagem significativa, que esta seja capaz de introduzir o estudante de língua estrangeira em ao menos parte da cultura da língua-alvo, estabelecendo relações e desta forma ressignificando o aprendizado.

Em busca de um ensino de qualidade e da capacitação dos estudantes para a atuação no mercado de trabalho e para as mais diversas situações de comunicação em língua estrangeira, os professores de idiomas têm utilizado as mais diversas técnicas e metodologias de ensino. Muito já foi discutido a respeito do assunto, que ainda é tema para inúmeros estudos e aplicações. Ao escolher uma metodologia de ensino, o profissional deve considerar diversos aspectos inerentes ao grupo que irá participar das aulas. Características como faixa etária, número de alunos, objetivos específicos do curso, conhecimento prévio e língua materna podem indicar que abordagem o professor poderá adotar para a elaboração e desenvolvimento das aulas. Venturi (2006, p. 123) comenta que a artificialidade do ambiente de sala de aula, suscitada por métodos também artificiais, denota as causas do insucesso da aprendizagem.

Há uma grande variedade de possibilidades quando se fala em metodologias de ensino de língua estrangeira. Desde abordagens mais tradicionais com foco na estrutura da língua, passando por abordagens centradas no estudante e em suas construções a partir de eventos comunicativos, as propostas de ensino de idiomas têm sido desenvolvidas há muito tempo e vêm sendo utilizadas nas mais diversas modalidades de ensino.

Além de observar as diferentes metodologias para a organização do curso, há também outras avaliações a serem feitas. Observar a faixa etária do grupo, por exemplo, permite que o foco temático das aulas seja dirigido com mais facilidade e precisão. Essa proposta de ensino viria ao encontro das necessidades primordiais para o grupo no momento da aprendizagem, estabelecendo ligações com sua realidade pessoal e profissional, pilar inerente ao ESP. Mesmo uma investigação inicial sobre as preferências dos alunos pode tornar o momento da interação mais prazeroso e significativo. 
Ao tomar conhecimento do perfil da turma e objetivos do curso, o professor precisa ter uma clara noção de como a língua estrangeira deve ser abordada. Assim, lembramos que, segundo Lima (2007, p. 19), a ação pedagógica implica uma relação especial em que o estudante se apropria do conhecimento. Para tanto, o educador necessita adequar sua prática pedagógica às possibilidades de desenvolvimento e de aprendizagem de seus educandos.

Ao apresentar novas possibilidades de aprendizado aos alunos, o professor precisa saber um pouco da realidade em que estão inseridos. Em relação à língua estrangeira, 0 contato, a exposição tanto à forma escrita quanto oral é fundamental e pode definir como esse aluno irá aprender o novo idioma.

A construção de um curso que tenha como objetivo a comunicação em língua estrangeira deve prever momentos que possibilitem a interação, o uso da língua-alvo, precisa promover momentos que demonstrem aos alunos a relevância dessa língua para sua vida pessoal e profissional, e ainda trazer informações contextualizadas sobre a cultura dos países falantes de tal língua. A abertura de possibilidades, a valorização do conhecimento prévio e objetivos claros podem facilitar o aprendizado de uma segunda língua. A proposta de ensino não deve manter-se presa apenas ao que já é conhecido pelos discentes, há que se expandir horizontes, acrescentar conhecimentos, associar novas informações às antigas e, quando necessário, reorganizar o pensamento em um novo modelo.

Ao sugerir que o ensino de língua estrangeira seja voltado para a formação integral do indivíduo, reforça-se que o seu aprendizado poderá levá-lo a novas ideias, expandir as possibilidades de pensamento e inseri-lo em um novo contexto, em que a cultura seja tão importante quanto os demais conhecimentos adquiridos.

A dificuldade na aprendizagem da segunda língua, principalmente em cursos de inglês instrumental, é uma queixa frequente, em parte por causa do curto prazo para a capacitação dos alunos para a leitura de textos específicos em língua estrangeira. É possível que não apenas a leitura, mas também a escrita, a fala e a compreensão auditiva em segunda língua possam ser prejudicadas na tentativa de desenvolver habilidades básicas em alunos de cursos instrumentais. Sabe-se que tal déficit pode ser causado pela falta de formação suficiente ou, ainda, pelo despreparo dos profissionais. Prática comum em aulas de língua estrangeira é o ensino da gramática da língua-alvo separado das demais estruturas e expressões linguísticas. Em relação à atuação do professor, Oxford (1989, p. $140-141$ ) diz que: 
Professores podem exercer grande influência sobre a atmosfera emocional da turma, de três formas distintas: mudando a estrutura social da turma, dando responsabilidades aos estudantes e fornecendo maior quantia de conversação naturalística e os ensinando a usar estratégias afetivas.

Com a prática de atividades focadas apenas no estudo gramatical, os alunos podem estar sendo privados do acesso a situações reais de uso da língua e experiências concretas de prática da leitura e escrita. Rebelo (2008, p. 274) cita Just e Carpenter (1987) quando afirmam que o conjunto formado por texto, atividade e objetivos de leitura tem forte influência sobre o que é aprendido durante seu exercício, e que aquilo que se aprende depende da atividade de aprendizagem utilizada. Sendo assim, é possível que o aprendizado dos alunos quando não focado em atividades textuais elaboradas a partir de materiais autênticos, com gênero $e$ temática voltados para a área específica da formação ofertada pelo curso, possa ser comprometido ou prejudicado de alguma forma. A proposta de ensino diversificada e atenta às respostas dos estudantes tende a gerar resultados mais positivos.

\section{Considerações Finais}

Neste artigo buscamos refletir sobre o ensino de língua inglesa como língua estrangeira a partir da proposta de ensino de línguas para propósitos específicos (BASTKURMEN, 2010, RAMOS, 2004, VILAÇA, 2010, JOHNS \& PRICE-MACHADO, 2001). Após apresentarmos um breve histórico do ensino técnico no país e como o ensino de línguas estrangeiras se insere nesse contexto, nos ocupamos em definir objetivos e prioridades, bem como metodologias apropriadas às especificidades do público-alvo.

Verificamos que pode haver um aumento na motivação dos estudantes para a manutenção de seus estudos na língua estrangeira quando o conhecimento adquirido faz sentido em sua realidade (LIMA, 2007). Hoje vemos que os estudantes ingressantes em cursos técnicos de caráter pós-médio apresentam grandes limitações em seus conhecimentos em língua estrangeira, visto que foram pouco expostos a situações de contato com a língua e que nem sempre as metodologias de ensino utilizadas pelos professores são adequadas aos grupos escolares. 
Entendemos que o ensino de línguas estrangeiras e da leitura em cursos técnicos continua sendo de grande valor para os futuros trabalhadores (OLIVEIRA, 2011, FERRAZ, 2012, BEZERRA, 2012). A formação profissional não pode permitir que a formação pessoal e linguística sejam deixadas em segundo plano. Para obter sucesso e demonstrar habilidades diferenciadas em seu trabalho, os técnicos precisam ter habilidades comunicativas bem desenvolvidas tanto em sua língua materna quanto na língua estrangeira. Enfim, a leitura deve ser vista tanto como ato pessoal, quanto social, abrindo portas, capacitando profissionais e, além de tudo, sendo forma de expansão das possibilidades de crescimento.

\section{Referências}

ALMEIDA FILHO, J. C. P. de. Dimensões comunicativas no ensino de línguas. Campinas: Pontes, 1993.

ARNT, J. T. Representações da língua inglesa e da multimodalidade no ensino médio integrado: implicações para uma pedagogia de multiletramentos. Tese de doutorado Universidade Federal de Santa Maria - UFSM, Santa Maria, 2018.

BADDELEY, A. A Aprendizagem. In: BADDELEY, A, ANDERSON, M.C, EYSENCK, M.W. Memória. Porto Alegre: Artmed, 2011.

BASTKURMEN, H. Developing courses in English for Specific Purposes. Palgrave Macmillan, 2010.

BENCKE, D. B. Estratégias de compreensão leitora em português brasileiro e em inglês como segunda língua um estudo comparativo sobre transferência linguística no âmbito da metacognição. Dissertação de mestrado - Universidade de Santa Cruz do Sul - UNISC, Santa Cruz do Sul, 2008.

BEZERRA, D. de S. Políticas e planejamento do ensino médio (integrado ao técnico) e da língua estrangeira (inglês): na mira(gem) da politecnia e da integação. Tese de doutorado Universidade de São Paulo - USP, São Paulo, 2012.

BRASIL. Secretaria de Educação Profissional e Tecnológica. Um novo modelo em educação profissional e tecnológica: concepção e diretrizes. Brasília: Ministério da Educação, 2010.

BRASIL. Conselho Nacional de Educação - Câmara de Educação Básica. Diretrizes operacionais para a educação profissional em nível nacional. Brasília: Ministério da Educação, 1997. 
BRAUER, K. C. N. O emprego das estratégias de leitura em textos de inglês como LE. Dissertação de mestrado - Universidade de Santa Cruz do Sul - UNISC, Santa Cruz do Sul, 2009.

BROUGHTON, G., et al. Teaching English as a foreign language. New York: Routledge, 1980.

BROWN, D. H. Principles of language learning and teaching. Third Edition. New Jersey: Prentice Hall Regents, 1994.

FERRAZ, D. de M. Educação de língua inglesa e novos letramentos: espaços de mudanças por meio dos ensinos técnicos e tecnológicos. Tese de doutorado - Universidade de São Paulo USP, São Paulo, 2012.

IZQQUIERDO, I. Memória. 3 ed. Porto Alegre: Artmed, 2018

JOHNS, A., PRICE-MACHADO, D. English for Specific Purposes: Tailoring Courses to Student Needs - and to the Outside World. In: CELCE-MURCIA, M. (Ed.) Teaching English as a Second or Foreign Language. Third Edition. Boston: Heinle \& Heinle, 2001.

KANDEL, E.R. et al. Princípios de neurociências. 5 ed. Porto Alegre: AMGH, 2014.

LADO, Robert. Language teaching: a scientific approach. New York: McGraw-Hill do Brasil, 1964 .

LEFFA, V. J. Língua estrangeira hegemônica e solidariedade internacional. In: KARWOSKI, Acir Mário; BONI, Valéria de Fátima Carvalho Vaz (Orgs.). Tendências contemporâneas no ensino de inglês. União da Vitória, PR: Kaygangue, 2006, p. 10-25.

LIMA, E. S. Indagações sobre currículo: currículo e desenvolvimento humano. Brasília: Ministério da Educação, Secretaria de Educação Básica, 2007.

MATSUDA, A. Principles and Practices of teaching English as an International Language. Multilingual Matters, 2012.

MARCUSCHI, L. A. Produção textual, análise de gêneros e compreensão. São Paulo: Parábola, 2008.

MEIRELES, C. M. da S. Das artes e officios à educação tecnológica: 90 anos de história. Pelotas: Ed. Da UFPEL, 2007.

MORAIS, J. A arte de ler. Trad. Álvaro Lorencini. São Paulo: Editora da Universidade Estadual Paulista, 1996.

OLIVEIRA, F. O ensino de língua inglesa, a política e os cursos técnicos. Semina: Ciências Sociais e Humanas. V. 32, $n^{0} 2$, Londrina, 2011, p. 143-156 
O'MALLEY, J. M.; CHAMOT, A. U. Learning strategies in second language acquisition. New York: Cambridge University Press, 1990.

OXFORD, R. L. Language Learning Strategies: What every teacher should know. Alabama: Heinle \& Heinle Publishers, 1989.

RAMOS, Rosinda de Castro Guerra Ramos. Gêneros textuais: uma proposta de aplicação em cursos de inglês para fins específicos. The ESPecialist, vol. 25, n², 2004.

REBELO, Letícia Z. As atividades de Leitura no Ensino de Inglês Instrumental. In: TOMITCH, Lêda M. B. Aspectos cognitivos e instrucionais da leitura. Bauru, EDUSC, 2008.

SANTOS, Denise. Ensino de língua inglesa: foco em estratégias. Barueri: DISAL, 2012.

SAVIGNON, Sandra J. Communicative Competence: Theory and Classroom practice. Massachusetts: Addison-Wesley Publishing Company, 1983.

SILVA, Célia E. da. O processo de compreensão na leitura em língua estrangeira: relato de uma experiência com alunos de $2^{\circ}$ grau. São Paulo, USP, 2002.

SMITH, Frank. Compreendendo a leitura: uma análise psicolinguística da leitura e do aprender a ler. Porto Alegre: Artes Médicas, 1989.

SOUZA, Vilmar F. de. Cognatos, predição e compreensão leitora - revisitando velhos conceitos, construindo um novo diálogo. In: TOMITCH, Lêda M. B. Aspectos cognitivos e instrucionais da leitura. Bauru, EDUSC, 2008.

VENTURI, Maria Alice. Aquisição de língua estrangeira numa perspectiva de estudos aplicados. In: DEL RÉ, A. Aquisição da linguagem: uma abordagem psicolinguística. São Paulo: Contexto, 2006.

VILAÇA, Marcio L. C. English for Specific Purposes: fundamentos do ensino de inglês para fins específicos. Revista Eletrônica do Instituto de Humanidades, N. 34. Rio de Janeiro: Unigranrio, 2010.

Data de submissão: 07/09/2019. Data de aprovação: 29/10/2019. 